\title{
Semi-automatic detection of myocardial trabeculation using cardiovascular magnetic resonance: correlation with histology and reproducibility in a mouse model of non-compaction
}

Julien Frandon ${ }^{1,2,3^{*}} \mathbb{D}$, Stéphanie Bricq ${ }^{4}$, Zakarya Bentatou' ${ }^{1}$, Laetitia Marcadet ${ }^{5}$, Pierre Antoine Barral², Mathieu Finas ${ }^{1}$, Daniel Fagret ${ }^{6}$, Frank Kober ${ }^{1}$, Gilbert Habib${ }^{7}$, Monique Bernard ${ }^{1}$, Alain Lalande ${ }^{4,8}$, Lucile Miquerol ${ }^{4}$ and Alexis Jacquier ${ }^{1,2}$

\begin{abstract}
Background: The definition of left ventricular (LV) non-compaction is controversial, and discriminating between normal and excessive LV trabeculation remains challenging. Our goal was to quantify LV trabeculation on cardiovascular magnetic resonance (CMR) images in a genetic mouse model of non-compaction using a dedicated semi-automatic software package and to compare our results to the histology used as a gold standard.

Methods: Adult mice with ventricular non-compaction were generated by conditional trabecular deletion of Nkx2-5. Thirteen mice ( 5 controls, 8 Nkx2-5 mutants) were included in the study. Cine CMR series were acquired in the mid LV short axis plane (resolution $0.086 \times 0.086 \times 1 \mathrm{~mm}^{3}$ ) $(11.75 \mathrm{~T}$ ). In a sub set of 6 mice, 5 to 7 cine CMR were acquired in LV short axis to cover the whole LV with a lower resolution $(0.172 \times 0.172 \times 1 \mathrm{~mm} 3)$. We used semi-automatic software to quantify the compacted mass $\left(M_{c}\right)$, the trabeculated mass $\left(M_{t}\right)$ and the percentage of trabeculation $\left(M_{t} / M_{c}\right)$ on all cine acquisitions. After CMR all hearts were sliced along the short axis and stained with eosin, and histological LV contouring was performed manually, blinded from the CMR results, and $M_{t}, M_{c}$ and $M_{t} / M_{c}$ were quantified. Intra and interobserver reproducibility was evaluated by computing the intra class correlation coefficient (ICC).
\end{abstract}

Results: Whole heart acquisition showed no statistical significant difference between trabeculation measured at the basal, midventricular and apical parts of the LV. On the mid-LV cine CMR slice, the median $\mathrm{M}_{\mathrm{t}}$ was $0.92 \mathrm{mg}$ (range 0.07-2. $56 \mathrm{mg}), M_{c}$ was $12.24 \mathrm{mg}$ (9.58-17.51 mg), $M_{t} / M_{c}$ was 6.74\% (0.66-17.33\%). There was a strong correlation between CMR and the histology for $M_{t}, M_{c}$ and $M_{t} / M_{c}$ with respectively: $r^{2}=0.94(p<0.001), r^{2}=0.91(p<0.001), r^{2}=0.83(p<0.001)$. Intra- and interobserver reproducibility was 0.97 and 0.8 for $M_{t ;} ; 0.98$ and 0.97 for $M_{c} ; 0.96$ and 0.72 for $M_{t} / M_{c}$ respectively and significantly more trabeculation was observed in the $M_{c}$ Mutant mice than the controls.

Conclusion: The proposed semi-automatic quantification software is accurate in comparison to the histology and reproducible in evaluating $M_{c}, M_{t}$ and $M_{t} / M_{c}$ on cine CMR.

Keywords: Left ventricular non-compaction, Semi-automatic segmentation, CMR, Genetic mouse model, CMR

\footnotetext{
*Correspondence: jfrandon38@gmail.com; julien.frandon@chu-nimes.fr

${ }^{1}$ Aix-Marseille University, CNRS, CRMBM, Marseille, France

${ }^{2}$ Department of Radiology, Timone University Hospital, Marseille, France

Full list of author information is available at the end of the article
}

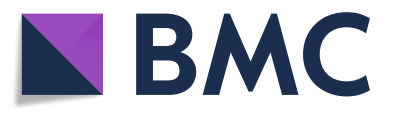

(c) The Author(s). 2018 Open Access This article is distributed under the terms of the Creative Commons Attribution 4.0 International License (http://creativecommons.org/licenses/by/4.0/), which permits unrestricted use, distribution, and reproduction in any medium, provided you give appropriate credit to the original author(s) and the source, provide a link to the Creative Commons license, and indicate if changes were made. The Creative Commons Public Domain Dedication waiver (http://creativecommons.org/publicdomain/zero/1.0/) applies to the data made available in this article, unless otherwise stated. 


\section{Background}

Left ventricular (LV) non-compaction (LVNC) is suspected on echocardiography or cardiovascular magnetic resonance (CMR) when a characteristic double-layered aspect of the myocardium with a thick, non-compacted endocardial layer, prominent trabeculations and deep recesses are observed [1-3]. Untreated, LVNC can lead to heart failure, cardioembolic events, and tachyarythmia; it may occur as an isolated cardiomyopathy or in association with other congenital heart diseases [4]. Quantification of the total amount of LV trabeculation on CMR has been proposed as a method to diagnose $\operatorname{LVNC}[3,5]$, but manual contouring of all LV trabeculation and compacted LV is time consuming. Recently, Bricq et al. developed a semi-automatic software package to calculate the non-compacted mass $\left(\mathrm{M}_{\mathrm{t}}\right)$ that suppresses blood from the trabeculae and evaluate the total amount of LV trabeculation as well as LV mass [6]. The feasibility of this trabeculation quantification algorithm was illustrated in a small group of mice along with their histology data, but no assessment of reproducibility or validation in an animal group of sufficient size was provided.

In this study, the quantification software was compared with histology and tested for accuracy and reproducibility in a mouse model of non-compaction. Nkx2-5 is a homeodomain transcription factor, which drives the early stages of cardiac morphogenesis. Global $N k x 2-5$ knock-out in mice causes early embryonic lethality with delayed cardiac development $[7,8]$, though heterozygous Nkx2-5 knock-out mice present a spectrum of cardiac anomalies including signs of ventricular non-compaction and cardiac conduction system defects [8-11]. A previous animal study has shown that inducible ventricular knock-out of $N k x 2-5$ generates adult mice with an LVNC phenotype [12]. Mutations of $N k x 2-5$ have been identified in numerous patients with congenital heart diseases, and some were associated with LVNC [13]. Our goal was to quantify LV trabeculation on CMR in a genetic mouse model of non-compaction using a dedicated semi-automatic software package and to compare our results to the histology used as a gold standard.

\section{Methods}

\section{Conditional trabecular Nkx2-5 knock-out mouse model}

(Fig. 1)

The animal procedures were approved by the University's ethics committee for animal experimentation $\left(\mathrm{n}^{\circ}\right.$ 40-10,102,012). Animal care was given in compliance with the national and institutional guidelines and this study was performed under the authorization of the local ethical committee. Mice were part of the project "mouse cardiovascular development system" $\left(\mathrm{n}^{\circ}\right.$ 01055.02). During embryonic development, Connexin-40 (Cx40) is expressed in the trabeculae, therefore we crossed $N k x 2-5$ floxed mice [11] with $\mathrm{Cx} 40^{\text {cre/+ }}$ mice to allow Cre-inducible deletion of the floxed gene specifically in the trabeculae [14]. Cre recombinase mediated-deletion of the Nkx2-5-Flox gene was induced with tamoxifen $(20 \mathrm{mg} / \mathrm{ml}$, Sigma-Aldrich, St. Louis, Missouri, USA) injected intraperitoneally [15] into pregnant mice $(200 \mu \mathrm{L})$ for 2 consecutive days or once subcutaneously at 1 day postnatally (P1) $(20 \mu \mathrm{L})$. The first day of gestation was defined as the morning on which the vaginal plug was found. Thirteen mice were analyzed

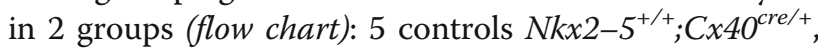
and 8 mutant mice: 3 heterozygous $N k \times 2-5^{+/-} ; C x 40^{\text {cre/+ }}$ [9], and 5 homozygous $N k x 2-5^{\text {flox/- }} ; C x 40^{\text {cre/+ }}$ at different stages (4 injected at embryonic stages, and 1 at P1). All mice were sacrificed after CMR and whole hearts were dissected and sectioned in the transversal axis using a cryostat. The eosin stained slices were incubated for $5 \mathrm{~min}$ in a $5 \%$ aqueous solution (Sigma-Aldrich).

\section{CMR}

CMR scans were performed on adult mice when they weighed 20-30 g, i.e. after 2 to 4 months depending on the strains, using a preclinical $11.75 \mathrm{~T}$ system (AVANCE $500 \mathrm{MHz} / 89 \mathrm{~mm}$ wide bore vertical imager (11.75 Bruker Biospin $\mathrm{GmbH}$, Ettlingen, Germany) and a $30 \mathrm{~mm}$ diameter transmit-receive radiofrequency resonator. Anesthesia was maintained during CMR with $1-2 \%$ isoflurane in a constant flow of ambient air $(270 \mathrm{ml} / \mathrm{min})$ through a nose cone using a dedicated vaporizer (Univentor anaesthesia unit, Univentor high precision instruments, Zejtun, Malta). Body temperature was maintained at $37^{\circ} \mathrm{C}$. Respiration rate and heart rate were monitored and the signals were used to trigger the CMR acquisitions using a monitoring and gating system (SA Instruments, Inc. Stony Brook, New York, USA). High resolution spoiled gradient echo cine CMR (repetition time $15 \mathrm{~ms}$, echo time $1.68 \mathrm{~ms}$, flip angle $30^{\circ}$, slice thickness $1 \mathrm{~mm}$, in-plane resolution $0.086 \times 0.086 \mathrm{~mm}^{2}$ ) was performed in short axis view, at mid base-apex level.

In a subset of 6 mice ( 1 control, 5 mutant), whole heart spoiled gradient echo cine CMR with lower spatial resolution was added to the high resolution acquisition (repetition time $5 \mathrm{~ms}$, echo time $1.51 \mathrm{~ms}$, flip angle $20^{\circ}$, slice thickness $1 \mathrm{~mm}$, in-plane resolution $0.172 \times 0.172 \mathrm{~mm}^{2}$ ) in short axis view. Five to seven slices were acquired from base to apex to cover the whole left ventricle. The end-diastolic frames were segmented with the software to assess the extent of the trabeculation across LV.

\section{Image analysis}

For the evaluation of LV trabeculation, the end diastolic frame from the cine imaging was used to segment the myocardium with the dedicated software previously described 


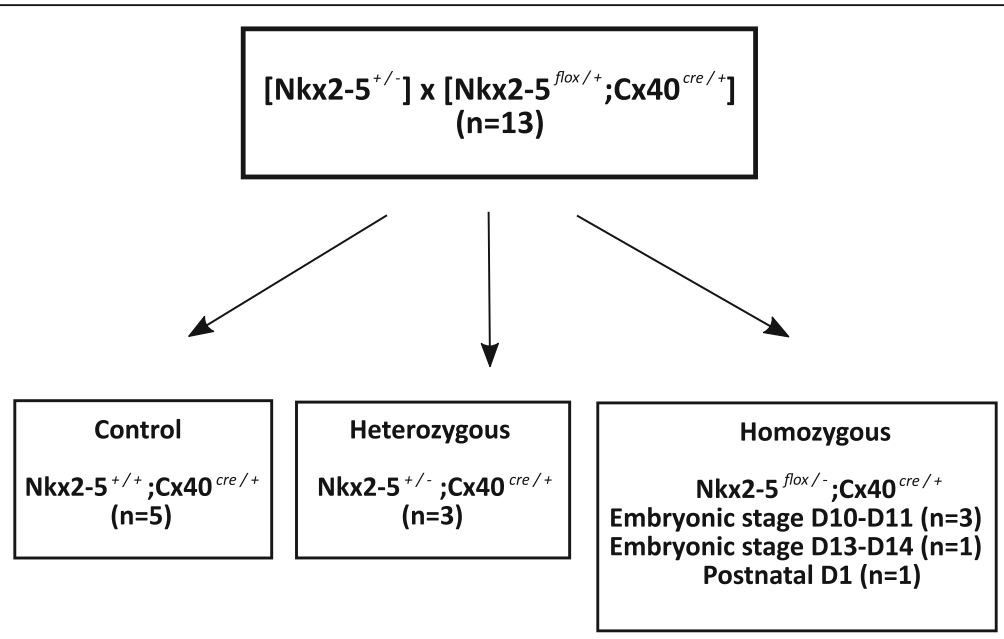

Fig. 1 Flow chart

[6]. The method requires a seed indicated by the user to initialize the selected slice. The non-compacted region was obtained using this seed and a region-growing algorithm. This non-compacted contour was then used to initialize an active contour to determine the endocardial and epicardial borders. When necessary, each contour was manually corrected. The papillary muscles were then segmented using a semi-automatic threshold tool based on the difference between bright blood and darker myocardial intensities. Afterwards, blood was removed from the trabeculae using the same thresholding tool. The trabeculae were defined at the end-diastolic phase as dark myocardium protruding from the LV wall into the bright LV cavity. Papillary muscles were included in the myocardial mass. If the papillary muscles could not be clearly distinguished from the trabeculation on the short-axis images, they were treated as trabeculation (Fig. 2) [6].

The trabeculated area $\left(\mathrm{M}_{\mathrm{t}}\right)$ was defined as the area including all LV trabeculations excluding the papillary muscles and LV blood between the trabeculae. Compacted area $\left(M_{c}\right)$ was defined by the myocardial area including the papillary muscles and excluding LV trabeculation. The knowledge of the slice thickness of $1 \mathrm{~mm}$ allows the calculation of the trabeculated and compacted mass in each slice. Percentage of LV trabeculation $\left(\mathrm{M}_{\mathrm{t}} / \mathrm{M}_{\mathrm{c}}\right)$ was expressed as a percentage of the trabeculated area computed by $\mathrm{M}_{\mathrm{t}} / \mathrm{M}_{\mathrm{c}} \times 100$.

To investigate intraobserver variability, observer 1 (J.F., 5 years of experience) repeated the measurements on 10 cine images at least 1 month after the first examination to minimize recall bias. A second independent observer (Z.B., 2 years of experience) repeated the different measurements on the same acquisitions to assess interobserver variability.

All mice were sacrificed after CMR and whole hearts were dissected and sectioned in the transversal axis using a cryostat. Cryosections were $20 \mu \mathrm{m}$ thick. From these cryosections, we visually selected the one that best corresponded to the CMR slice level. Papillary muscle shape and size and trabeculation distribution were selected as land marks to perform a visual co-registration between CMR and the histology. In the subset of 6 mice, 5 to 7 histological sections were selected per animal to be consistent with the 5 to 7 CMR stacks acquired from base to apex using the same co-registration method.

Each histological slice was analyzed by observer 1 (J.F.) who was blinded to the CMR results. The segmentation was done manually with Image J (version $1.49 \mathrm{v}$, National Institute of Health, Bethesda, Maryland, USA) using the same segmentation procedure (Fig. 2).

\section{Statistical analysis}

All mouse group characteristics are reported as median values and range. The values were compared between the groups using Kruskal-Wallis and Mann Whitney U tests. The results were considered as significant when $p<.05$. Linear regression and Pearson correlation coefficients between the histology and CMR were assessed. The histological and CMR results for $M_{c}, M_{t}$ and $M_{t} / M_{c}$ were compared using Bland-Altman analysis and taking the histological data as a reference. Interobserver and intraobserver reproducibilities were assessed by computing the intraclass correlation coefficient (ICC) with a confidence interval (CI) of 95\% using Bland-Altman analysis.

\section{Results}

\section{Mice characteristics}

There were no significant differences between the control and mutant groups in terms of age, body weight or heart weight (Table 1). CMR was feasible with a good quality of image in all mice. A total of 13 cine images were evaluated. CMR was performed 

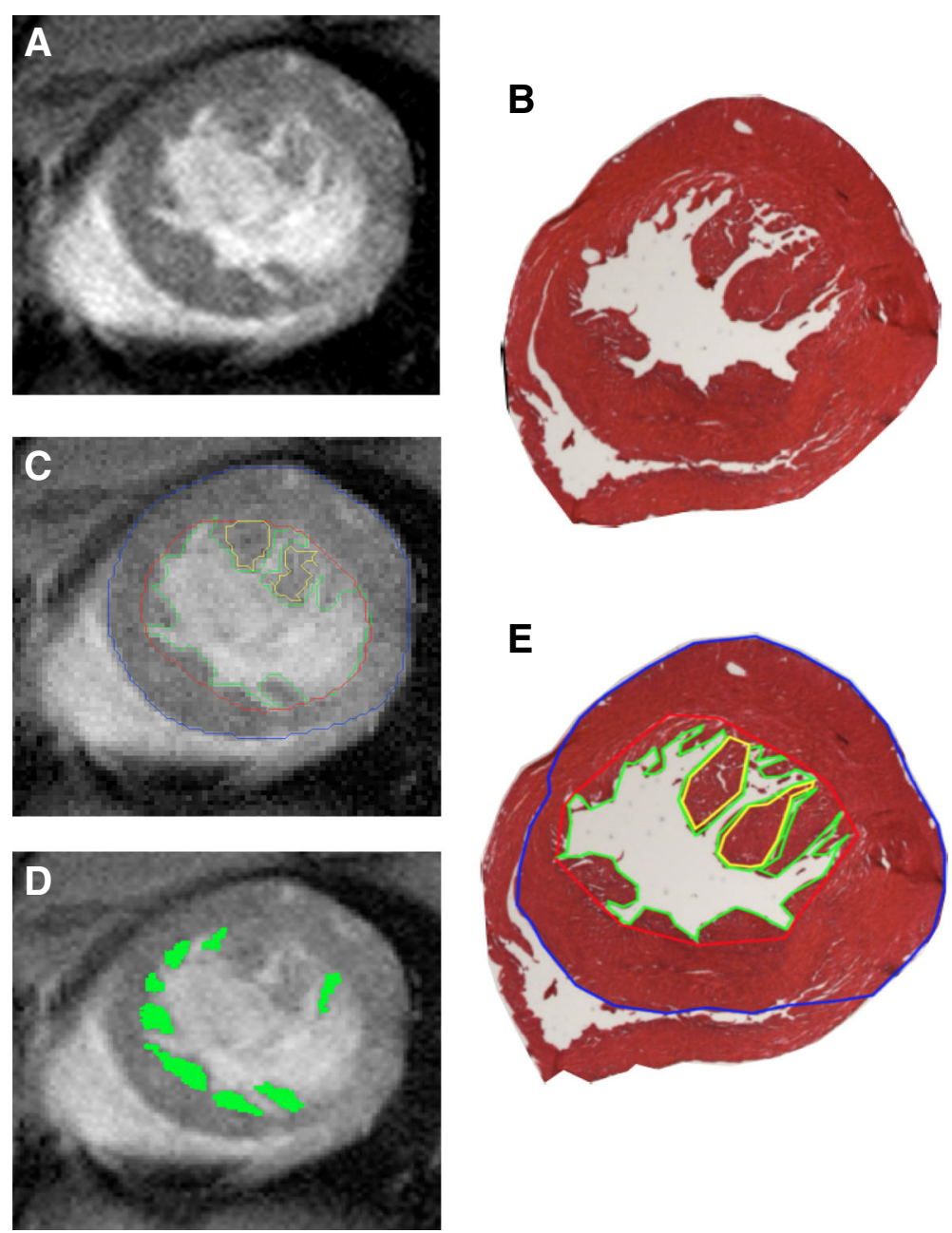

Fig. 2 Example of left ventricular (LV) high resolution CMR segmentation and corresponding eosin stained histological images. a-b: Example of a midventricular short axis, cine image from a mutant mouse heart (a) and slice at the same level from eosin stained histological slide (b). c-d: Semi-automatic LV segmentation of the cine image: the epicardial border appears in blue, the endocardial border in red, the trabecular border in green (c) and the trabecular surface in green (d). The papillary muscles were segmented and included in the compacted area (yellow line) (c). e: Manual LV segmentation of the histological slice using the same segmentation procedure: epicardial border in blue, endocardial border in red, trabecular border in green. The papillary muscles were segmented and included in the compacted area (yellow line)

on adult mice on median day 63 (range: 47-120 days). Median body and heart weight at the time of CMR were $26.5 \mathrm{~g}$ (range 16.5-34.0 g) and $185 \mathrm{mg}$ (range 124-233 mg), respectively. Histological staining was successful in all cases.

Table 1 Mice characteristics at time of CMR: median values (min-max)

\begin{tabular}{llll}
\hline & Control $(n=5)$ & Mutant $(n=8)$ & P value \\
\hline $\begin{array}{l}\text { Age at time of } \\
\text { CMR (days) }\end{array}$ & $118(60-120)$ & $60(47-112)$ & 0.17 \\
$\begin{array}{l}\text { Total weight }(\mathrm{g}) \\
\text { Heart weight }(\mathrm{mg})\end{array}$ & $30.6(24-33)$ & $24(16.5-34)$ & 0.30 \\
\hline
\end{tabular}

\section{Study of trabeculation across the whole LV}

Processing took $15 \pm 0.5 \mathrm{~min}$ for one whole heart examination, including computation time and user interaction. Automatic epicardial, endocardial and trabeculation border detection took less than 1 min per slice. Semi automatic papillary muscles detection took less than $30 \mathrm{~s}$, whereas around $1.5 \mathrm{~min}$ were required to segment blood within the trabeculation net per slice (Fig. 3).

The results of whole heart segmentation for $M_{t}, M_{c}$ and $\mathrm{M}_{\mathrm{t}} / \mathrm{M}_{\mathrm{c}}$ are summarized in Table 2. There was no statistical difference between basal, midventricular and apical parts for $\mathrm{M}_{\mathrm{t}}(p=0.61), \mathrm{M}_{\mathrm{c}}(p=0.48)$ and $\mathrm{M}_{\mathrm{t}} / \mathrm{M}_{\mathrm{c}}(p=0.35)$.

The results of the Bland-Altman test performed with the histological data as reference showed good agreement with 


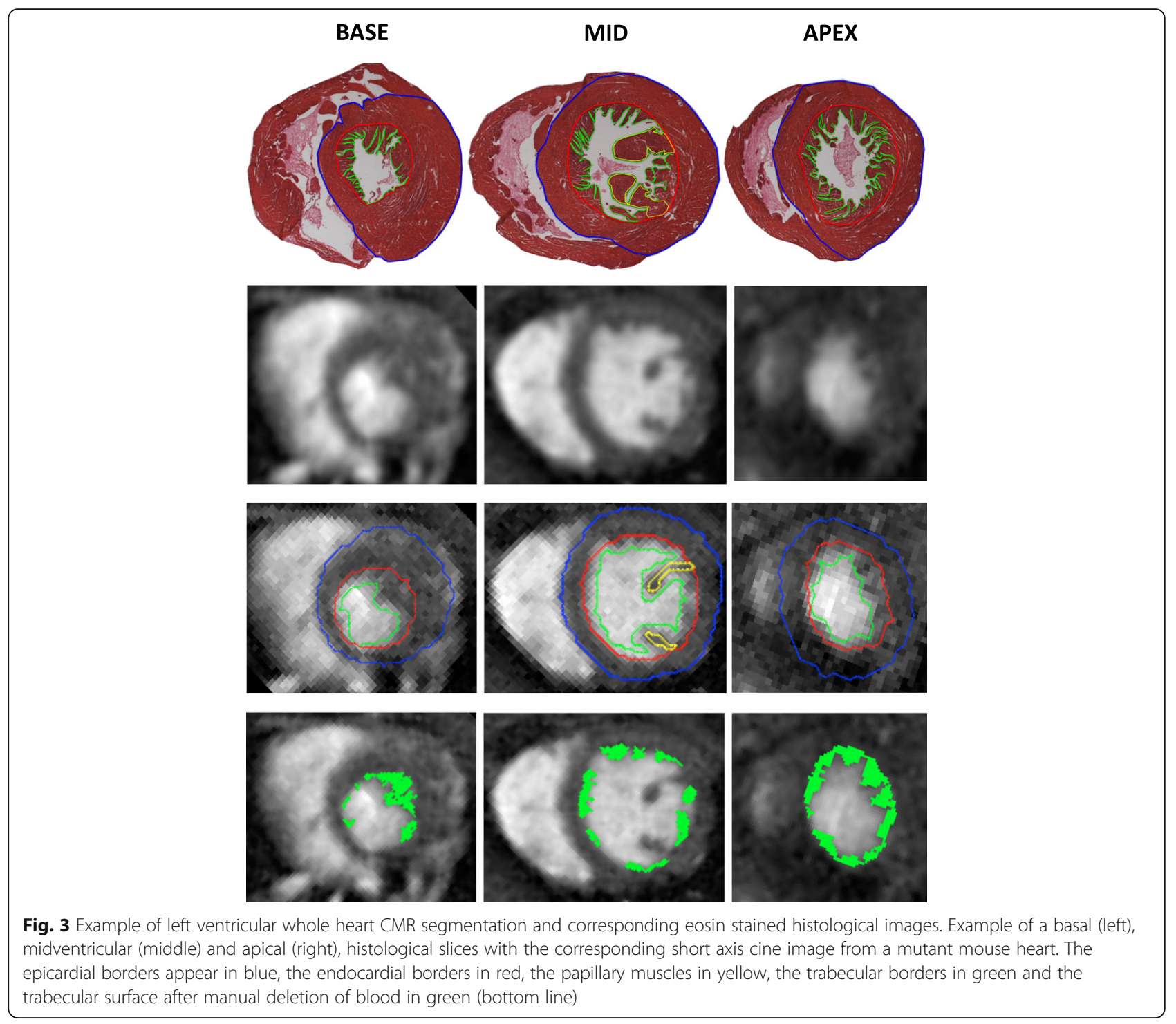

Table 2 Trabeculae segmentation: whole heart CMR vs histology

\begin{tabular}{llll}
\hline & $C M R$ & Histology & $P$ value \\
\hline $\begin{array}{l}\text { Whole heart } M_{t}(m g) \\
\text { median values }(m i n-m a x)\end{array}$ & $6.31(4.76-10.22)$ & $4.68(2.3-8.4)$ & 0.16 \\
Apical $M_{t}(m g)$ & $2.68(1.56-4)$ & $1.68(0.6-2.93)$ & 0.86 \\
Midventricular $M_{t}(m g)$ & $2.59(1.57-5)$ & $1.75(0.65-2.47$ & 0.94 \\
Basal $M_{t}(m g)$ & $2.28(1.21-5)$ & $0.97(0.36-2.06)$ & 0.41 \\
Whole heart $M_{c}(m g)$ & $57.52(36.72-90.8)$ & $52.13(34.63-86.59)$ & 0.7 \\
Apical $M_{c}(m g)$ & $17.07(8.87-27)$ & $17.13(12.26-25.97)$ & 0.89 \\
Midventricular $M_{c}(m g)$ & $24.1(15.73-30)$ & $21.7(16.09-32.34)$ & 0.56 \\
Basal $M_{c}(m g)$ & $19.42(12.1-29.5)$ & $17.95(7.12-28.28)$ & 0.73 \\
Whole heart $M_{t} / M_{c}(\%)$ & $12.95(6.36-17.57)$ & $9.19(3.12-16)$ & 0.75 \\
Apical $M_{t} / M_{c}(\%)$ & $15.75(7.61-33.03)$ & $10.85(7.15-23.9)$ & 0.9 \\
Midventricular $M_{t} / M_{c}(\%)$ & $10.59(6.9-16.67)$ & $8.51(2.51-12.02)$ & 0.73 \\
Basal $M_{t} / M_{c}(\%)$ & $9.12(7.99-14.67)$ & $5.4(3.66-7.67)$ & 0.44 \\
\hline
\end{tabular}


a subtle overestimation of myocardial mass compared to the histology: $+1.89 \pm 1.08 \mathrm{mg}$ for $\mathrm{M}_{\mathrm{c}},+4.26 \pm 2 \mathrm{mg}$ for $\mathrm{M}_{\mathrm{c}}$ and $+2.35 \pm 1.83 \%$ for $\mathrm{M}_{\mathrm{t}} / \mathrm{M}_{\mathrm{c}}$. There was a strong correlation between the histology and the whole heart cine imaging for $\mathrm{M}_{\mathrm{c}}: \mathrm{r}^{2}=0.98(p<0.001)$; and good for $\mathrm{M}_{\mathrm{t}}: \mathrm{r}^{2}=$ $0.74(p=0.017) ;$ and $\mathrm{M}_{\mathrm{t}} / \mathrm{M}_{\mathrm{c}}: \mathrm{r}^{2}=0.81(p=0.009)$.

\section{Trabecular segmentation and histological correlation on high resolution CMR}

Segmentation was feasible in all mice (Table 3). The median value of $\mathrm{M}_{\mathrm{t}}$ in all mice by CMR showed a high agreement with histology (0.92 mg CMR vs $0.8 \mathrm{mg}$ histology, $\left.r^{2}=0.94, p<0.001\right)$. The median value of $\mathrm{M}_{\mathrm{c}}$ in all mice by CMR showed a high agreement with histology (12.24 mg CMR vs $12.16 \mathrm{mg}$ histology, $\mathrm{r}^{2}=$ $0.91, p<0.001)$. The median value of $\mathrm{M}_{\mathrm{t}} / \mathrm{M}_{\mathrm{c}}$ in all mice by CMR showed a good agreement with histology (6.74\% CMR vs $6.17 \%$ histology, $\mathrm{r}^{2}=0.83, p<0.001$, Table 3, Fig. 4). The results of the Bland-Altman test using the histological data as a reference showed high agreement (Fig. 4).

\section{Intra- and interobserver reproducibility}

Intraobserver reproducibility assessed by ICC was high for $\mathrm{M}_{\mathrm{t}}, \mathrm{M}_{\mathrm{c}}$ and $\mathrm{M}_{\mathrm{t}} / \mathrm{M}_{\mathrm{c}}$ with 0.97 (0.6-0.99), 0.98 (0.94-0.99) and $0.93(0.84-0.97)$, respectively (Fig. 5). Interobserver reproducibility was high for $\mathrm{M}_{\mathrm{c}}: 0.97(0.88-0.99)$ and moderate for $\mathrm{M}_{\mathrm{t}}$ and $\mathrm{M}_{\mathrm{t}} / \mathrm{M}_{\mathrm{c}}: 0.80$ (0.55-0.85), 0.72 (0.49$0.85)$, respectively. The results of the Bland-Altman analysis comparing the 2 observers showed very good agreement with a mean difference close to $0: 0.01 \pm$ $0.54 \mathrm{mg}$ (coefficient of variation: $\pm 33.23 \%$ ) for $\mathrm{M}_{\mathrm{t}}, 0.63 \pm$ $0.45 \mathrm{mg}( \pm 7.63 \%)$ for $\mathrm{M}_{\mathrm{c}}$ and $-0.56 \pm 4.14 \%( \pm 37.69 \%)$ for $\mathrm{M}_{\mathrm{t}} / \mathrm{M}_{\mathrm{c}}$.

\section{Trabecular segmentation and mutant mice on high resolution CMR}

The $M_{c}$ part of the myocardium from the CMR mid-LV cine images showed no significant difference when the mutant mice: median $12.17 \mathrm{mg}$ (range 9.58-17.51 mg) were compared to the control mice $12.24 \mathrm{mg}$ (range 10.63-12.98 mg) ( $p=0.94$ ) (Table 4). The $\mathrm{M}_{\mathrm{t}}$ and $\mathrm{M}_{\mathrm{t}} / \mathrm{M}_{\mathrm{c}}$ calculated using CMR were significantly higher in the mutants in comparison to the control mice with $1.66 \mathrm{mg}$ (range $0.5-2.56 \mathrm{mg}$ ) vs $0.65 \mathrm{mg}$ (range 0.07 -

Table 3 Trabeculae segmentation: high resolution CMR vs histology

\begin{tabular}{llll}
\hline & $C M R$ & Histology & $P$ value \\
\hline$M_{t}(m g)$ & $0.92(0.07-2.56)$ & $0.8(0.4-2.23)$ & 0.88 \\
median values (min-max) & & & \\
$M_{c}(m g)$ & $12.24(9.58-17.51)$ & $12.16(8.89-16.6)$ & 0.74 \\
$M_{t} / M_{c}(\%)$ & $6.74(0.66-17.33)$ & $6.17(3.42-14.45)$ & 0.83 \\
\hline
\end{tabular}

$0.71 \mathrm{mg})(p=0.02)$ for $\mathrm{M}_{\mathrm{t}}$; and $14.22 \%$ (range 2.86$17.33 \mathrm{mg}$ ) vs $5 \%$ (range $0.66-6.08 \%)(p=0.02)$ for $\mathrm{M}_{\mathrm{t}} /$ $\mathrm{M}_{\mathrm{c}}$ (Fig. 6).

\section{Discussion}

In this murine CMR study, we assessed the performance of a semi-automatic software program dedicated to the quantification of compacted, trabeculated mass and found a high correlation between the histology and CMR. The software also showed a low intra- and intrerobserver variability.

A few earlier studies assessed trabeculation in mice using different methods. Kosaka et al. assessed trabeculation by measuring the $M_{t}$ area [16], however, their histological validation was performed on sliced hearts in 4-chamber views. Yang et al. and Chen et al. also studied trabeculation in embryonic mice hearts $[17,18]$ by measuring $\mathrm{M}_{\mathrm{t}}$ thickness on histological pseudo 4-chamber slices. These data are difficult to compare with our results.

In our study, the LV of mice seemed to be less trabeculated compared to human LV with a more homogeneous distribution of trabeculation over the entire LV. In humans there is a basal to apical gradient with increase of trabeculation from base to apex $[6,19]$. In mice, the apical and midventricular part of the LV seemed to be hypertrabeculated. We chose a midventricular section for high resolution cine imaging to facilitate co registration with the histology using the papillary muscles as landmarks. A comparison between CMR and the histology was feasible in all mice and the correlation was high, however, the correlation with the histology was slightly lower than for the compacted part due to the small size and amount of trabeculation, partial volume effects and flow artifacts.

The software we used for this purpose quantifies trabeculation for the whole LV and requires just one click in the LV cavity to initialize the region-growing algorithm to detect the non-compacted borders. We used interactive thresholding to segment the papillary muscles and to extract blood from the non-compacted area. The software provided an accurate, reproducible, non-invasive semi-automatic calculation of LV compacted and trabeculated mass in adult mice on the cine imaging. We were able to show a significant increase of LV trabeculation in mice with conditional trabecular deletion of the Nkx2.5 gene compared to control mice. The semi-automatic software was capable of differentiating between control and mutant mice. Assessing the correlation between the amounts of trabeculae and clinical phenotypes may contribute to a better understanding of hypertrabeculation in humans.

The reproducibility for $\mathrm{M}_{\mathrm{c}}$ was high as shown earlier by Bricq et al. in their evaluation of normal trabeculation in humans (60 volunteers) [6]. Interobserver reproducibility was moderate for $M_{t}$ and $M_{t} / M_{c}$ mainly due to additive 
High resolution CMR and histological correlation

\section{$\mathrm{T}(\mathrm{mg})$}
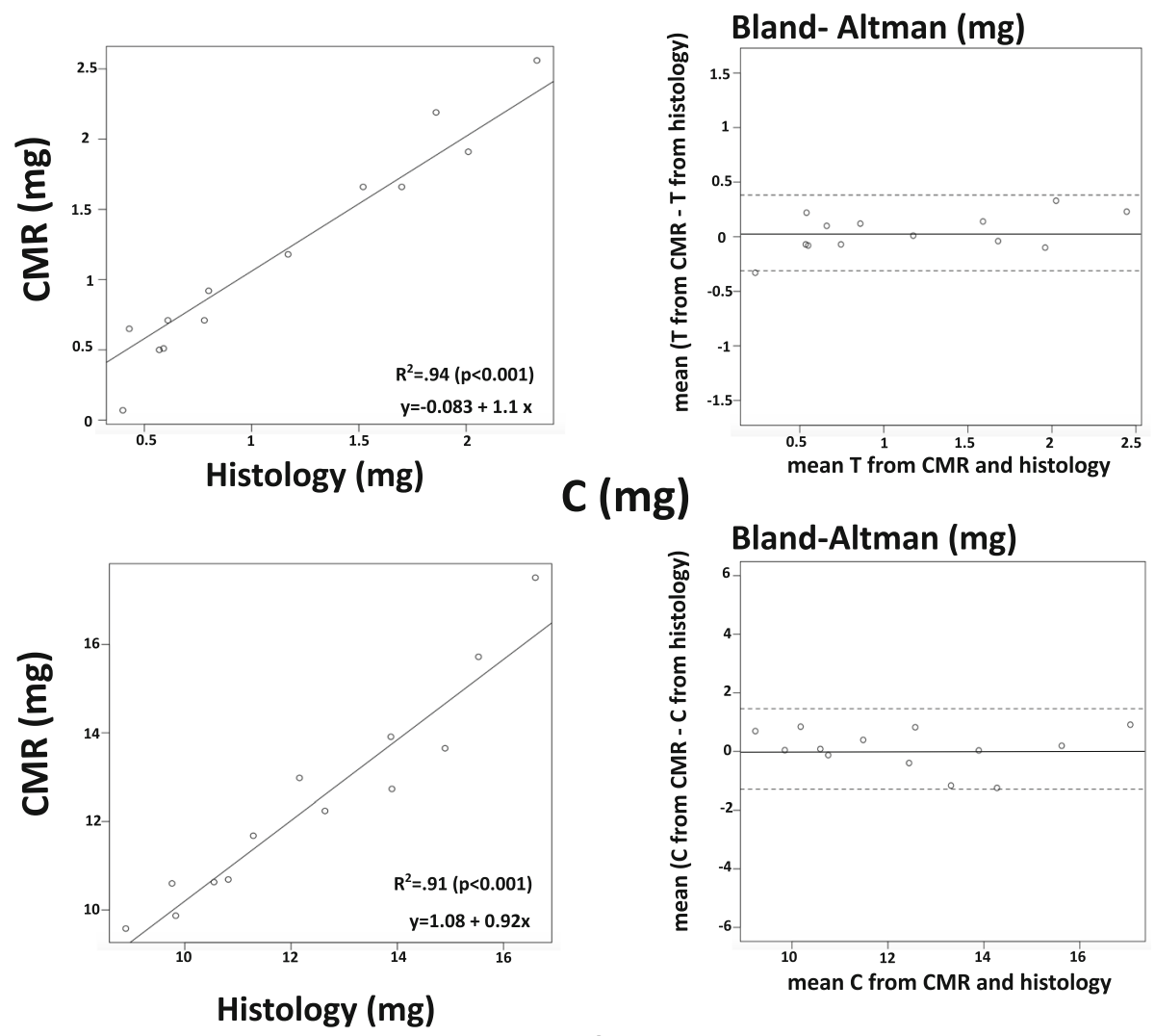

\section{$\mathrm{T} / \mathrm{C}(\%)$}
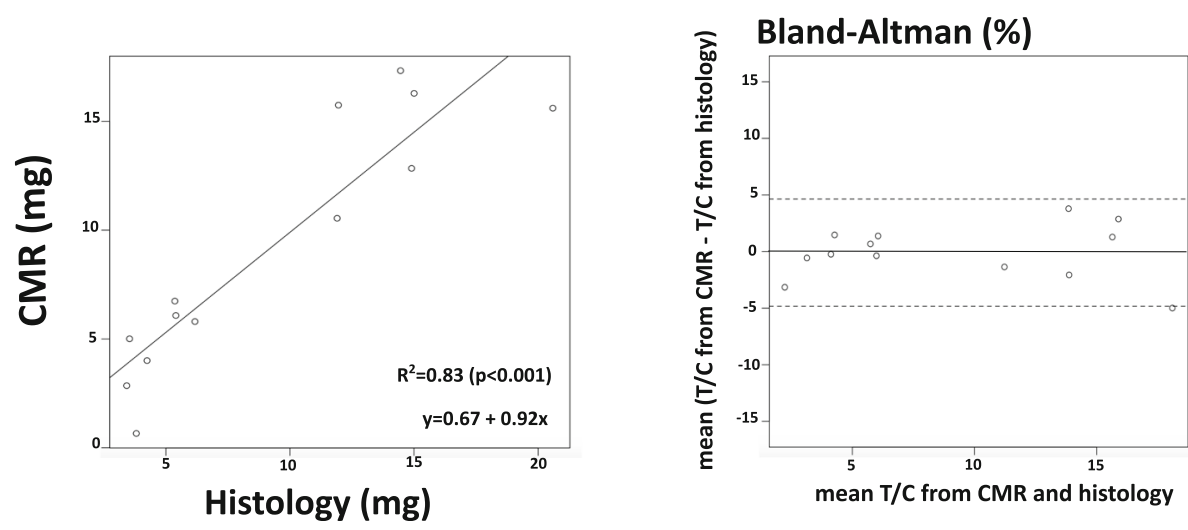

Fig. 4 Correlation between high resolution CMR and histology. Linear regression (left) showing the relationship between histology and CMR quantifications of $M_{t}(T)$ (top), $M_{c}(C)$ (middle) and $M_{t} / M_{c}(T / C)$ (bottom). Bland-Altman plots (right) showing the agreement between histology and CMR quantifications of T (top), C (middle) and T/C (bottom)

systematic measurement errors between $M_{t}$ and $M_{c}$. This could be explained by the difference of segmentation due to partial volume around trabecules between the two observers. Intraobserver reproducibility remained very high for $M_{t}, M_{c}$, and $M_{t} / M_{c}$; this emphasizes the necessity for a strict method of segmentation, notably for trabeculation.
Measurement variation for $M_{t}$ and $M_{t} / M_{c}$ could be clinically significant for small amounts of trabeculae.

The quantification of trabeculated mass has previously been used in several human studies assessing hypertrabeculation $[3,5,6]$. The global trabeculation ratio of $6.74 \%$ was low compared to human reference even for mutant 


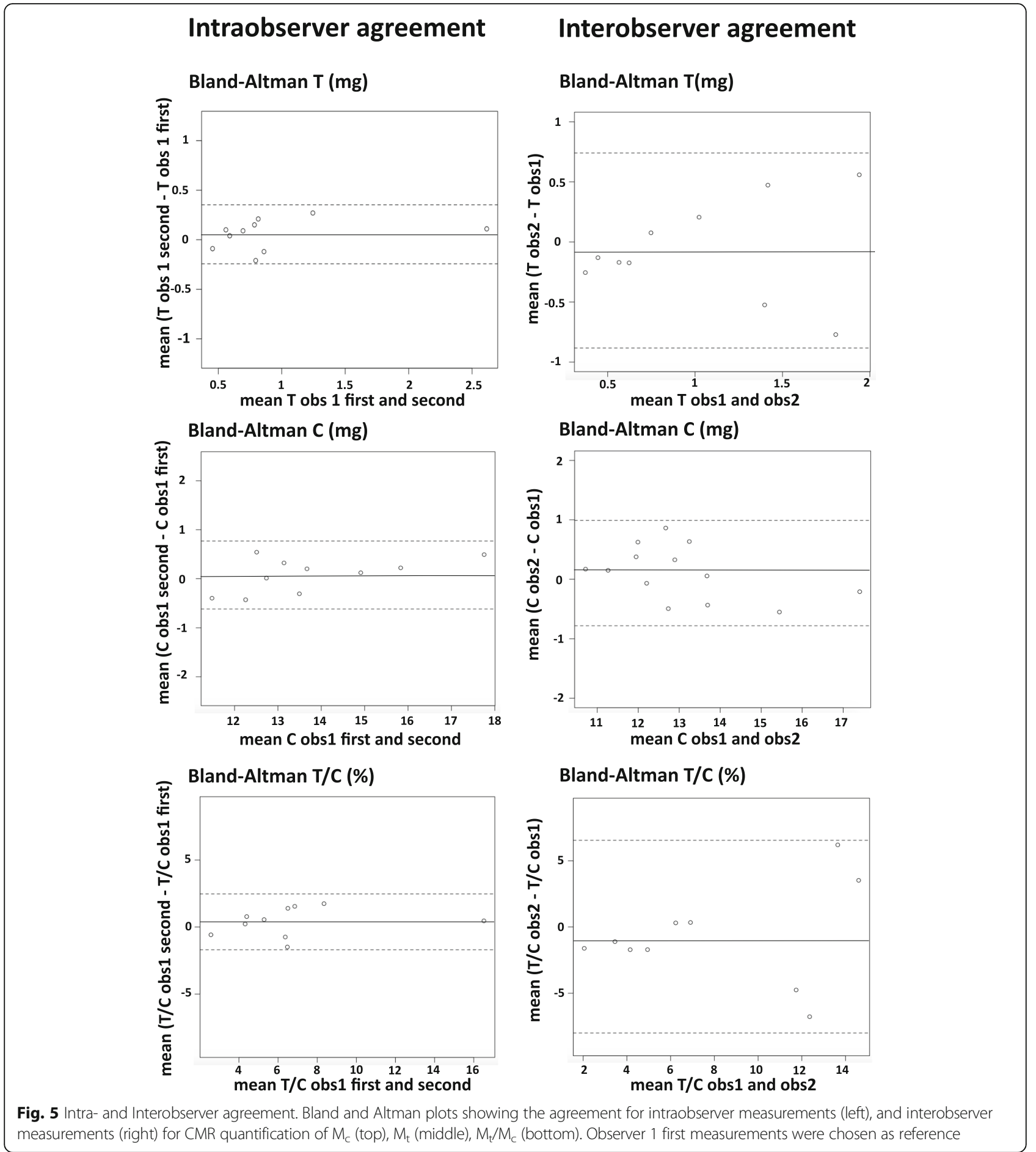

mice with a $\mathrm{T} / \mathrm{C}$ of $14.22 \%$. In their study on 60 healthy subjects, Briq et al. found a $M_{t} / M_{c}$ ratio of $10.26 \%$ with more trabeculation in the apex and lateral parts [6]. In human studies, the diagnosis of LVNC is still a matter of debate and there is no standard of reference for LV trabeculation quantification. Petersen et al. measured the
$\mathrm{M}_{\mathrm{t}} / \mathrm{M}_{\mathrm{c}}$ thickness on human subjects at the point where trabeculation was the most pronounced [2]. A threshold $\mathrm{M}_{\mathrm{t}} / \mathrm{M}_{\mathrm{c}}$ thickness of 2.3 has been proposed to diagnose non-compaction [2], however Kawel et al. have shown that $43 \%$ healthy subjects from the Multiethnic Study of Atherosclerosis (MESA) Study have a $M_{t} / M_{c}>2.3$ [19]. In this 
Table 4 Trabecular segmentation on high resolution CMR: control vs mutant mice

\begin{tabular}{llll}
\hline & Control $(\mathrm{n}=5)$ & Mutant $(\mathrm{n}=8)$ & $P$ value \\
\hline $\begin{array}{l}M_{\mathrm{t}} \text { from histology }(\mathrm{mg}) \\
\text { median values (min-max) }\end{array}$ & $0.59(0.04-0.78)$ & $1.61(0.57-2.33)$ & $\mathbf{0 . 0 1}$ \\
$M_{\mathrm{t}}$ from CMR (mg) & $0.65(0.07-0.71)$ & $1.66(0.5-2.56)$ & $\mathbf{0 . 0 2}$ \\
$M_{\mathrm{c}}$ from histology (mg) & $12.16(10.55-13.91)$ & $12.35(8.89-15.53)$ & 1.00 \\
$M_{c}$ from CMR (mg) & $12.24(10.63-12.98)$ & $12.17(9.58-17.51)$ & 0.94 \\
$M_{t} / M_{c}$ from histology (\%) & $4.24(3.54-6.17)$ & $13.72(3.43-19.12)$ & 0.06 \\
$M_{t} / M_{c}$ from CMR (\%) & $5.01(0.66-6.08)$ & $14.21(2.86-17.33)$ & $\mathbf{0 . 0 2}$ \\
\hline$P<.05$ indicte
\end{tabular}

$p<.05$ indicate entries in boldface

study, the evaluation was based on area segmentation and mass calculation. We arbitrarily selected a mid-LV slice to compare with the histological data. Captur et al. characterized the trabeculae differently, using a parameter correlated with LV endocardial complexity to calculate a fractal index that they applied to embryonic mice hearts by using high-resolution microscopy [20-22]. Hypertrabeculation is also a phenotype that could be encountered in several other cardiomyopathies such as hypertrophic cardiomopathy. Furthermore some first-degree relatives of patients with LVNC may express a hypertrabeculated phenotype. An accurate tool to quantify LV trabeculation could prove to be useful to define the phenotype of the patient more precisely.

The principal limitation of the study is the fact that our software is not fully automatic and this next step would require further resources such as artificial intelligence tools to allow completely automated segmentation of LV trabeculation. The co-registration between CMR and histology was carried out visually. Despite the care and accuracy we put into that step a misregistration bias may have been included.

Furthermore, we quantify trabeculation as a mass. This is an approximation of the truth due to the partial volume effect. $M_{t}$ seen on CMR may not always extend through the entire thickness of the slice. It is more likely that trabeculation represents a partial volume through the slice thickness. What we express as $\mathrm{M}_{\mathrm{t}}$ is thus some uncertain value between blood and myocardium. To be consistent with the literature we have used the term trabeculated mass.

The method requires assessment in clinical practice to define cut off values for normal LV trabeculation and excess trabeculation.

\section{Conclusions}

The proposed post-processing software allowed accurate and reproducible quantification of the amount of LV trabeculation in mice from CMR. In comparison to the histology, the semi-automatic software was accurate in its evaluation of $M_{c}, M_{t}$ and $M_{t} / M_{c}$. Trabeculation seems to increase dramatically when the deletion of the $N k x 2.5$ gene is induced at different embryonic development stages.

\section{Clinical competences}

This study assesses the accuracy and reproducibility of a new software program to evaluate left ventricular $T$. The semi-automatic software shows a high degree of accuracy and reproducibility compared to the histology as a

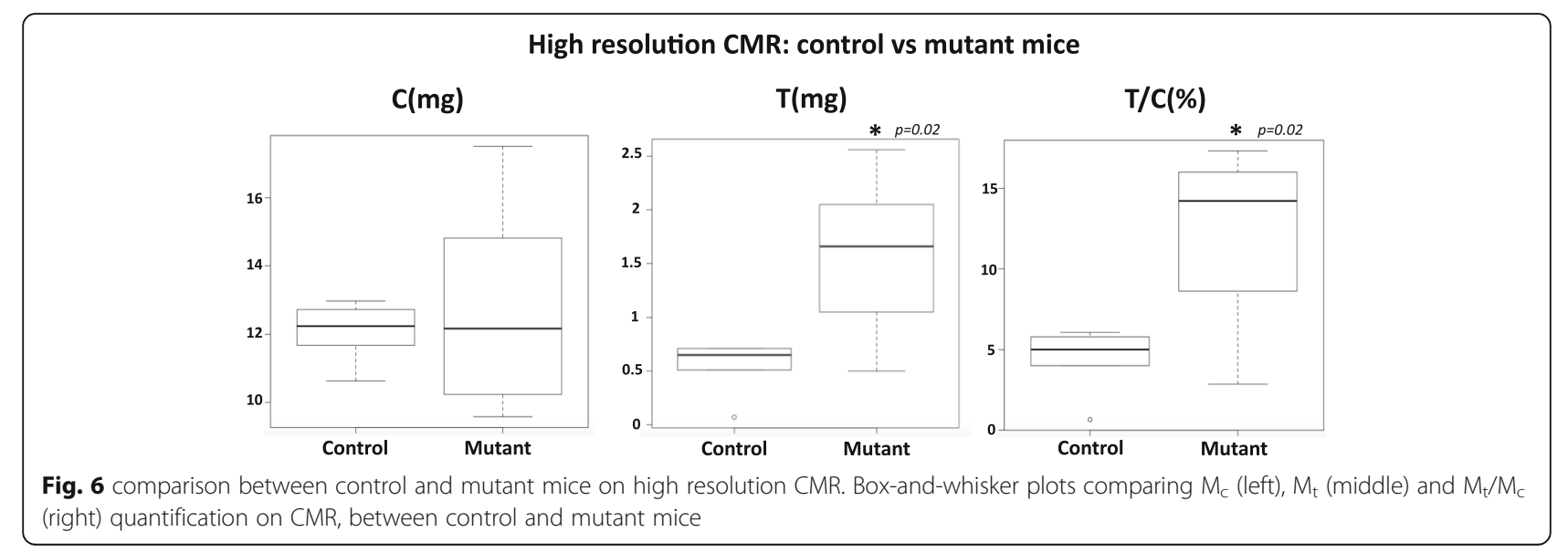


reference. This software program could be used in humans to quantify the total amount of trabeculation.

\section{Translational outlook}

We showed that it was possible to assess trabeculation in a non-invasive manner and that we could differentiate mutant from control mice. LV non-compaction remains controversial and has no gold standard diagnosis. This semi-automatic software could help to discriminate normal from hypertrabeculated patients due to its accuracy in calculating the amount of LV trabeculation.

\section{Abbreviations}

$\mathrm{Cl}$ : Confidence interval; CMR: Cardiovascular magnetic resonance; Cx40: Connexin 40; D: Day; ICC: Intra-class correlation coefficient; LV: Left ventricle/left ventricular; LVEF: Left ventricular ejection fraction; LVNC: Left ventricular non-compaction; $M_{c}$ : Compacted mass; $M_{t} / M_{c}$ : Percent of trabeculation computed by $M_{t} / M_{c} \times 100 ; M_{t}$ : Trabeculated mass; P1: Postnatal day 1; PCR: Polymerase chain reaction; RV: Right ventricle/right ventricular

\section{Funding}

Julien Frandon was supported by a grant provided by the Société Française de Radiologie - French Society of Radiology - (SFR) together with the Collège des Enseignants en Radiologie de France - French Academic College of Radiology - (CERF)

This work was performed by a laboratory member of France Life Imaging network (grant ANR-11-INBS-0006)

\section{Availability of data and materials}

All datas and materials are available. Please contact for data requests.

\section{Authors' contributions}

JF: conception and design of the study, acquisition of data, analysis and interpretation of data, drafting the manuscript. LM, MF, ZB: acquisition of data, analysis and interpretation of data. $S B, A L, M B, P A B, F K, L M, A J$ : conception and design of the study, revision of manuscript. SB, AL: Management of the post-processing tools. DF, GH: revision of manuscript. All authors read and approved the final manuscript.

\section{Ethics approval}

The animal procedures were approved by the University's ethics committee for animal experimentation ( $\left.n^{\circ} 40-10,102,012\right)$. Animal care was given in compliance with the national and institutional guidelines and this study was performed under the authorization of the local ethical committee. Mice were part of the project "mouse cardiovascular development system" $\left(\mathrm{n}^{\circ}\right.$ 01055.02).

\section{Consent for publication}

Not applicable

\section{Competing interests}

The authors declare that they have no competing interests.

\section{Publisher's Note}

Springer Nature remains neutral with regard to jurisdictional claims in published maps and institutional affiliations.

\footnotetext{
Author details

${ }^{1}$ Aix-Marseille University, CNRS, CRMBM, Marseille, France. ${ }^{2}$ Department of Radiology, Timone University Hospital, Marseille, France. ${ }^{3}$ Department of Radiology, Nîmes University Hospital, Nîmes, France. ${ }^{4}$ Le2i, Université de Bourgogne Franche-Comté, Dijon, France. ${ }^{5}$ CNRS UMR 7288, Developmental Biology Institute of Marseille, Aix-Marseille University, Marseille, France. ${ }^{6}$ INSERM, U1039, Radiopharmaceutiques Biocliniques, Université Grenoble Alpes, Grenoble, France. ${ }^{7}$ Department of Cardiology, APHM, la Timone
}

Hospital, Marseille, France. ${ }^{8}$ Department of MRI, University Hospital Francois Mitterrand, Dijon, France.

Received: 18 January 2018 Accepted: 5 September 2018 Published online: 25 October 2018

\section{References}

1. Jenni R, Oechslin E, Schneider J, Attenhofer Jost C, Kaufmann PA. Echocardiographic and pathoanatomical characteristics of isolated left ventricular non-compaction: a step towards classification as a distinct cardiomyopathy. Heart. 2001;86:666-71.

2. Petersen SE, Selvanayagam JB, Wiesmann F, Robson MD, Francis JM, Anderson $\mathrm{RH}$, et al. Left ventricular non-compaction: insights from cardiovascular magnetic resonance imaging. J Am Coll Cardiol. 2005. https://doi.org/10.1016/j.jacc.2005.03.045.

3. Jacquier A, Thuny F, Jop B, Giorgi R, Cohen F, Gaubert J-Y, et al. Measurement of trabeculated left ventricular mass using cardiac magnetic resonance imaging in the diagnosis of left ventricular non-compaction. Eur Heart J. 2010. https://doi.org/10.1093/eurheartj/ehp595.

4. Hussein A, Karimianpour A, Collier P, Krasuski RA. Isolated noncompaction of the left ventricle in adults. J Am Coll Cardiol. 2015. https://doi.org/10.1016/j. jacc.2015.06.017

5. Grothoff M, Pachowsky M, Hoffmann J, Posch M, Klaassen S, Lehmkuhl L, et al. Value of cardiovascular MR in diagnosing left ventricular non-compaction cardiomyopathy and in discriminating between other cardiomyopathies. Eur Radiol. 2012. https://doi.org/10.1007/s00330-012-2554-7.

6. Brica S, Frandon J, Bernard M, Guye M, Finas M, Marcadet $L$, et al. Semiautomatic detection of myocardial contours in order to investigate normal values of the left ventricular trabeculated mass using MRI. J Magn Reson Imaging. 2015. https://doi.org/10.1002/jmri.25113.

7. Briggs LE, Takeda M, Cuadra AE, Wakimoto H, Marks MH, Walker AJ, et al. Perinatal loss of Nkx2-5 results in rapid conduction and contraction defects. Circ Res. 2008. https://doi.org/10.1161/CIRCRESAHA.108.171835.

8. Tanaka M, Chen Z, Bartunkova S, Yamasaki N, Izumo S. The cardiac homeobox gene Csx/Nkx2.5 lies genetically upstream of multiple genes essential for heart development. Development. 1999;126:1269-80.

9. Meysen S, Marger L, Hewett KW, Jarry-Guichard T, Agarkova I, Chauvin JP, et al. Nkx2.5 cell-autonomous gene function is required for the postnatal formation of the peripheral ventricular conduction system. Dev Biol. 2007. https://doi.org/10.1016/j.ydbio.2006.12.044.

10. Jay PY, Harris BS, Maguire CT, Buerger A, Wakimoto H, Tanaka M, et al. Nkx25 mutation causes anatomic hypoplasia of the cardiac conduction system. J Clin Invest. 2004. https://doi.org/10.1172/JCl19846.

11. Furtado MB, Wilmanns JC, Chandran A, Tonta M, Biben C, Eichenlaub M, et al. A novel conditional mouse model for $\mathrm{Nkx2}-5$ reveals transcriptional regulation of cardiac ion channels. Differentiation. 2016. https://doi.org/10. 1016/j.diff.2015.12.003

12. Pashmforoush M, Lu JT, Chen H, Amand TS, Kondo R, Pradervand S, et al. Nkx2-5 pathways and congenital heart disease; loss of ventricular myocyte lineage specification leads to progressive cardiomyopathy and complete heart block. Cell. 2004;117:373-86.

13. Ashraf $H$, Pradhan L, Chang El, Terada R, Ryan NJ, Briggs LE, et al. A mouse model of human congenital heart disease: high incidence of diverse cardiac anomalies and ventricular noncompaction produced by heterozygous Nkx25 homeodomain missense mutation. Circ Cardiovasc Genet. 2014. https:// doi.org/10.1161/CIRCGENETICS.113.000281.

14. Miquerol L, Moreno-Rascon N, Beyer S, Dupays L, Meilhac SM, Buckingham $\mathrm{ME}$, et al. Biphasic development of the mammalian ventricular conduction system. Circ Res. 2010. https://doi.org/10.1161/CIRCRESAHA.110.218156.

15. Beyer S, Kelly RG, Miquerol L. Inducible Cx40-Cre expression in the cardiac conduction system and arterial endothelial cells. Genesis. 2011. https://doi. org/10.1002/dvg.20687.

16. Kosaka Y, Cieslik KA, Li L, Lezin G, Maguire CT, Saijoh Y, et al. 14-3-3ع plays a role in cardiac ventricular compaction by regulating the cardiomyocyte cell cycle. Mol Cell Biol. 2012. https://doi.org/10.1128/MCB.00829-12.

17. Yang J, Bücker $S$, Jungblut B, Böttger T, Cinnamon Y, Tchorz J, et al. Inhibition of Notch2 by numb/Numblike controls myocardial compaction in the heart. Cardiovasc Res. 2012. https://doi.org/10.1093/cvr/cvs250.

18. Chen $H$, Zhang W, Sun X, Yoshimoto $M$, Chen Z, Zhu W, et al. Fkbpla controls ventricular myocardium trabeculation and compaction by 
regulating endocardial Notch1 activity. Development. 2013. https://doi.org/ 10.1242/dev.089920

19. Kawel N, Nacif M, Arai AE, Gomes AS, Hundley WG, Johnson WC, et al. Trabeculated (noncompacted) and compact myocardium in adults: the multi-ethnic study of atherosclerosis. Circ Cardiovasc Imaging. 2012. https:// doi.org/10.1161/CIRCIMAGING.111.971713.

20. Captur G, Muthurangu V, Cook C, Flett AS, Wilson R, Barison A, et al. Quantification of left ventricular trabeculae using fractal analysis. J Cardiovasc Magn Reson. 2013. https://doi.org/10.1186/1532-429X-15-36.

21. Captur G, Zemrak F, Muthurangu V, Petersen SE, Li C, Bassett P, et al. Fractal analysis of myocardial Trabeculations in 2547 study participants: multiethnic study of atherosclerosis. Radiology. 2015. https://doi.org/10.1148/ radiol.2015142948.

22. Captur G, Wilson R, Bennett MF, Luxán G, Nasis A, de la Pompa JL, et al. Morphogenesis of myocardial trabeculae in the mouse embryo. J Anat. 2016. https://doi.org/10.1111/joa.12465.

Ready to submit your research? Choose BMC and benefit from:

- fast, convenient online submission

- thorough peer review by experienced researchers in your field

- rapid publication on acceptance

- support for research data, including large and complex data types

- gold Open Access which fosters wider collaboration and increased citations

- maximum visibility for your research: over $100 \mathrm{M}$ website views per year

At $\mathrm{BMC}$, research is always in progress.

Learn more biomedcentral.com/submissions 